\title{
ANALYTICAL MODEL OF HVDC CONVERTERS IN DIRECT CONNECTION
}

\author{
José Daldegan $\mathrm{Jr}^{1}$ and Edson H. Watanabe ${ }^{2}$ \\ ${ }^{1}$ ELETRONORTE - Brazilian Holding Electric Power Co., Caixa Postal 04163, CEP 70.718-900 - Brasília - Brazil, \\ ${ }^{2}$ COPPE / Federal University of Rio de Janeiro, Caixa Postal 68504, CEP 21.945-970 - Rio de Janeiro - Brazil \\ daldegan@eln.gov.br, watanabe@coe.ufgj.br
}

\begin{abstract}
This paper presents an original analytical model for the direct connection of a HVDC converter to a synchronous generator, without $\mathrm{AC}$ filters and $\mathrm{AC}$ bus, usually referred to as Unit Connection. All the operation modes and its transition regions are precisely determined, which simplifies the usual analysis of this arrangement. Digital simulations of an equivalent traditional model, based on an electromagnetic transient program for DCAC systems, were used to validate the results.
\end{abstract}

Keywords - Direct Connection, HVDC Converter, Synchronous Machine, Unit Connection.

\section{INTRODUCTION}

Conventional HVDC transmission system is a very important solution for transmission of electric energy over a very long distance, a typical characteristic of the Brazilian electrical energy scenario, where three large projects has been studied (Madeira, Xingu and Tapajos rivers) and will be considered for the transmission from the Amazon to the Southeast and South Brazilian regions [1].

However, in this conventional HVDC system normally the generators are connected in a common bus with controlled frequency and with passive filter to eliminate harmonics. On the other hand, a possible simplest connection between an HVDC twelve-pulse converter and a synchronous generator can be done only through a transformer between them [1-6]. This configuration, usually referred to as "Direct Connection" or "Unit Connection" (UC), is shown in Figure 1 and has no passive filters and the generator does not need to operate at controlled frequency. The elimination of filters reduces cost and the possibility of variable frequency operation may improve efficiency of the generation system.

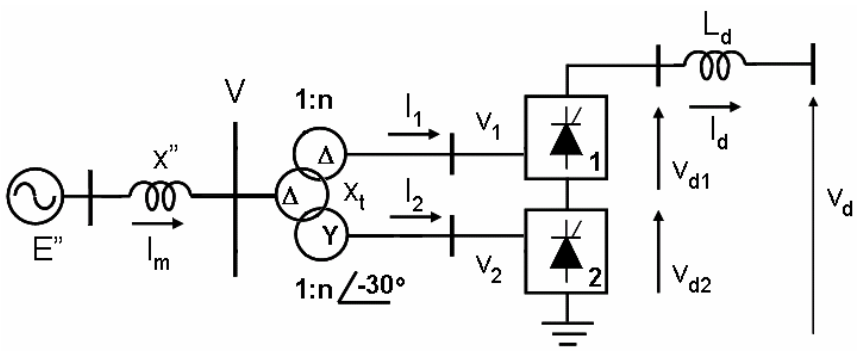

Fig. 1. Typical Unit Connected generator / HVDC system.

Manuscript received on 11/02/2008. Revised on 29/10/2008. Accepted by recommendation of the Editor Fernando L. M. Antunes.
In Unit Connection, despite the absence of AC filters, the sub-transient voltage of the machine is sinusoidal and is not affected by the current and voltage harmonic components generated by the converter, as demonstrated in [5]. This is the converter commutation voltage and is "behind" the commutation reactance, which includes the machine subtransient reactance and the transformer leakage reactance. In this case, the sub-transient saliency can be neglected [2-6].

As a result of this internal reactance, common to the two six-pulse bridges, commutations of an individual bridge cause distortions in the AC input voltage of the other bridge. This fact also occurs in conventional HVDC converters with the mutual reactance of three-winding transformers, amid the filter and the six-pulse bridges $[7,8]$.

The distortions in the machine terminal voltage cause a delay in the crossing of its phase voltages with respect to the sub-transient voltage. Thus, depending on the operating point, the firing angle has a minimum value greater than zero (represented in this paper by $\alpha_{\mathrm{m}}$ ), which corresponds to the well known natural (forced) delay angle $[5,7]$.

This influence of the sub-transient reactance produces new operation modes to the twelve-pulse converter and a new relation between commutation and minimum firing angles.

The objective of this paper is to present simple and original equations of rectifier voltage and direct current for all operation modes of Unit Connected generator / HVDC system, very useful to its whole design and to determine its optimal rated operating point.

This system presents some interesting operating characteristics, especially when diodes are used instead of thyristors. With this set of equations it is possible to see how to control the operating point of UC with diode valves by using the machine field voltage.

Simulation results obtained with an electromagnetic transient program [9] of an application of this control to a Diode based UC is presented. All the original equations of this paper are exhaustively and exclusively demonstrated in an extensive work of the authors [10].

The analytical model proposed in this paper is applicable to other arrangements as the direct connection in group, where there are many generators involved.

The technical and economical advantages and disadvantages of Unit Connection arrangement are very well discussed in the "Guide for Preliminary Design and Specification of Hydro Stations with HVDC Unit Connected Generators", prepared by a CICRÉ Joint Working Group [3]. 
TABLE I

Operation Modes and Transition Regions of Unit Connection

\begin{tabular}{ccccc}
\hline Region & Mode & Minimum Firing Angle & Commutation Angle & Superposition of commutations \\
\hline A & I & $\alpha_{\mathrm{m}}=0^{\circ}$ & $0^{\circ} \leq \mu \leq 30^{\circ}$ & There is no simultaneous commutations \\
\hline B & I or II & $0^{\circ} \leq \alpha_{\mathrm{m}} \leq \alpha_{\mathrm{c}}$ & $\mu=30^{\circ}$ & $\begin{array}{c}\text { Commutations happen sequentially; } \\
\text { at the end of one on Bridge } 1 \text {, another starts on Bridge } 2\end{array}$ \\
\hline C & II & $\alpha_{\mathrm{m}}=\alpha_{\mathrm{c}}$ & $30^{\circ} \leq \mu \leq 60^{\circ}$ & $\begin{array}{c}\text { Two commutations happen simultaneously } \\
\text { in part of the time }\end{array}$ \\
\hline D & II or III & $\alpha_{\mathrm{c}} \leq \alpha_{\mathrm{m}} \leq 30^{\circ}+\Delta \alpha$ & $\mu=60^{\circ}$ & $\begin{array}{c}\text { There are always superposition of two commutations; } \\
\text { at the end of one, another commutation starts }\end{array}$ \\
\hline E & III & $\alpha_{\mathrm{m}}=30^{\circ}+\Delta \alpha$ & $60^{\circ} \leq \mu \leq 90^{\circ}-\Delta \alpha$ & $\begin{array}{c}\text { Three commutations happen simultaneously } \\
\text { in part of the time }\end{array}$ \\
\hline F & IV & $\alpha_{\mathrm{m}}=30^{\circ}$ & $90^{\circ} \leq \mu \leq 120^{\circ}$ & $\begin{array}{c}\text { Four commutations happen simultaneously } \\
\text { in part of the time; two in each bridge }\end{array}$
\end{tabular}
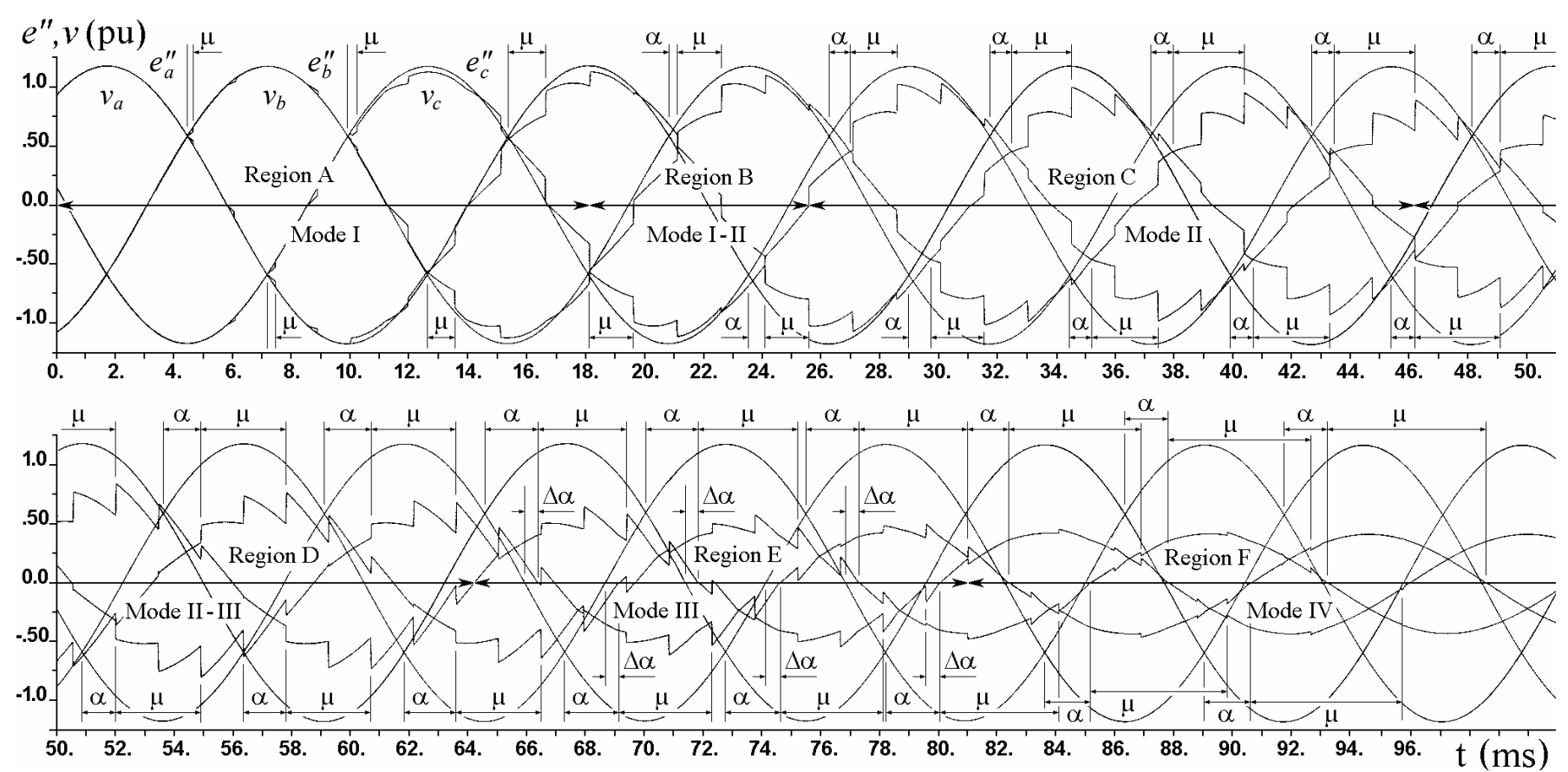

Fig. 2 - Evolution of machine terminal voltage across all UC operation modes and regions with increasing direct current.

\section{UC OPERATION MODES AND REGIONS}

The twelve-pulse converter in Unit Connection has six regions of operation, some of them with a clear minimum firing angle, an others with a fixed commutation angle. Some of these regions may not exist under determined conditions. These six regions can be grouped in four operation modes, with specific constitutive equations which are presented in this paper. These six regions and four modes are shown in Table I. The parameters $\alpha_{c}$ and $\Delta \alpha$ in this table are fixed and will be mathematically defined in sub-sections A and B.

Figure 2 reveals all intrinsic modes and regions of operation of the rectifier operating in Unit Connection. This figure was obtained by assuming that the firing angle $\alpha$ of the thyristors is as minimal as possible (like the natural delay angle in diode valves) and the current is increased from zero up to short-circuit level by the HVDC inverter control. The sinusoidal waveforms are the machine sub-transient voltages $e_{a}^{\prime \prime}, e_{b}^{\prime \prime}, e_{c}^{\prime,}$, and the distorted waveforms are the machine terminal voltages $v_{a}, v_{b}, v_{c}$.
As it is possible to show [10], the rectified average voltage and direct current of 12-pulse converter in Unit Connection, at any mode of operation, are given by:

$$
\begin{aligned}
& V_{d}=V_{d o}\{A[\cos (\alpha)+\cos (\alpha+\mu)]+B[\sin (\alpha)-\sin (\alpha+\mu)]\}, \\
& I_{d}=I_{d s c 2}\{C[\cos (\alpha)-\cos (\alpha+\mu)]+D[\sin (\alpha)+\sin (\alpha+\mu)]\},
\end{aligned}
$$

where the parameters $A, B, C$ and $D$ are presented later for each operation mode, but:

$$
\begin{gathered}
V_{d o}=3 \sqrt{2} E^{\prime \prime} / \pi, \\
I_{d s c 2}=\sqrt{2} E^{\prime \prime} / 2 X_{c},
\end{gathered}
$$

and:

$\alpha \quad$ - firing angle,

$\mu \quad$ - commutation angle,

$V_{d o} \quad$ - maximum six-pulse rectified voltage,

$I_{d s c 2}$ - two-phase short-circuit current,

$E^{\prime \prime} \quad$ - rms phase-to-phase sub-transient voltage,

$X_{\mathrm{c}}$ - commutation reactance. 
In (4), the commutation reactance $X_{c}$ (in ohms) includes the transformer leakage reactance $X_{t}$ and the generator subtransient reactance $X^{\prime \prime}$. This commutation reactance in pu (in per unit of the transformer's base impedance) is given by [2-5]:

$$
x_{c}=x_{t}+x^{\prime \prime} / 2,
$$

where $x_{t}$ is given in pu at the transformer basis and $x$ " is given in $\mathrm{pu}$ at the machine basis (for instance, $x " / 2$ is the generator sub-transient reactance in pu of the transformer's base impedance).

\section{A. Operation Mode I $\left(\mu \leq 30^{\circ}\right)$}

In the Operation Mode I, the commutations are not simultaneous (although it can be almost side by side). The 12-pulse rectified average voltage and direct current are given by Kimbark [7]. However, it can also be obtain from (1) and (2) with $A=C=1$ and $B=D=0$ :

$$
\begin{aligned}
& V_{d}=V_{d o}[\cos (\alpha)+\cos (\alpha+\mu)], \\
& I_{d}=I_{d s c 2}[\cos (\alpha)-\cos (\alpha+\mu)] .
\end{aligned}
$$

The commutation process is a time domain phenomenon; however, for these short intervals of time, with a sinusoidal commutation voltage, the utilization of the phasor notation as done by Kimbark [7] is very practical and perfectly feasible, as demonstrated in [5]. In Mode I, during commutation $c \rightarrow a$ (read: from phase $c$ to phase $a$ ) on bridge 1 (at $16 \mathrm{~ms}$ on Figure 2), for instance, the machine terminal voltages $v_{a}, v_{b}$, $v_{c}$, associated to sinusoidal sub-transient voltages $e_{a}^{\prime \prime}, e_{b}$, $e_{c}$, are defined by (in phasor notation):

$$
\begin{gathered}
\bar{V}_{a}=\bar{E}_{a}^{\prime \prime} \cdot k_{2} \angle \alpha_{c}, \\
\bar{V}_{b}=\bar{E}_{b}^{\prime \prime}, \\
\bar{V}_{c}=\bar{E}_{c}^{\prime \prime} \cdot k_{2} \angle-\alpha_{c}, \\
\bar{V}_{a c}=\bar{V}_{a}-\bar{V}_{c}=\bar{E}_{a c}^{\prime \prime} \cdot k_{1},
\end{gathered}
$$

Where, as demonstrated in [5]:

$$
\begin{gathered}
k_{1}=\left[x_{c}-\left(x^{\prime \prime} / 2\right)\right] / x_{c}=x_{t} / x_{c}, \\
k_{2}=\sqrt{1+3 k_{1}^{2}} / 2, \\
\alpha_{c}=\tan ^{-1}\left[\sqrt{3}\left(1-k_{1}\right) /\left(1+3 k_{1}\right)\right] .
\end{gathered}
$$

The parameter $k_{1}$ reflects the degree of independence between the two six-pulse bridges, despite the generator subtransient reactance; for instance, $K=\left[1-k_{1}\right]$ is named the coupling factor [8]. Angle $\alpha_{c}$ is the delay in the phases crossing of the machine terminal voltage.

During commutation from phase $c$ to $a$ on bridge 2 (at 17 ms on Figure 2), the machine terminal voltage is defined by:

$$
\begin{gathered}
\bar{V}_{a}=\bar{E}_{a}^{\prime \prime} \cdot k_{3} \angle \delta, \\
\bar{V}_{b}=\bar{E}_{b}^{\prime \prime} \cdot k_{3} \angle-\delta, \\
\bar{V}_{c}=\bar{E}_{c}^{\prime \prime} \cdot k_{1}, \\
\bar{V}_{a c}=\bar{E}_{a c}^{\prime \prime} \cdot k_{2} \angle \alpha_{c},
\end{gathered}
$$

where:

$$
\begin{gathered}
k_{3}=\sqrt{3+k_{1}^{2}} / 2, \\
\delta=\tan ^{-1}\left[\sqrt{3}\left(1-k_{1}\right) /\left(3+k_{1}\right)\right] .
\end{gathered}
$$

Mode I is very well characterized, in Figure 2, up to $18 \mathrm{~ms}$ (Region A), but its mathematical representation given above is valid up to $26 \mathrm{~ms}$, where the commutations are almost side by side and the minimum firing angle is variable (Region B).

\section{B. Operation Mode II $\left(30^{\circ} \leq \mu \leq 60^{\circ}\right)$}

In Mode II, also shown in Figure 2 (from $18 \mathrm{~ms}$ up to $64 \mathrm{~ms}$ ) and with more details in the Figure 3, the commutations on different bridges happen simultaneously in part of the time. During commutation $c \rightarrow a$ on bridge 1 (intervals 1 to 3 of Figure 3 ), commutation $a \rightarrow b$ on bridge 2 finishes (interval 1) and commutation $c \rightarrow a$ begins (interval 3 ) in this same bridge 2. Developing the utilization of the phasor notation, during commutations $c \rightarrow a$ on bridge 1 and $a \rightarrow b$ on bridge 2 (interval 1), the machine terminal voltage can be defined by the expressions below [10] (for $\alpha<\omega t<\alpha+\mu-\pi / 6$ ):

$$
\begin{gathered}
\bar{V}_{a c}=\bar{E}_{a c}^{\prime \prime} \cdot k_{1} \cdot k_{4} \angle-\alpha_{c}, \\
\bar{V}_{b}=\bar{E}_{b}^{\prime \prime} \cdot k_{5} \angle \Delta \alpha,
\end{gathered}
$$

where the angle $\Delta \alpha$ is the additional delay angle of the minimum-firing angle, and:

$$
\begin{gathered}
k_{4}=2 \sqrt{1+3 k_{1}^{2}} /\left(1+6 k_{1}-3 k_{1}^{2}\right), \\
k_{5}=\frac{k_{1} \sqrt{3\left(1-k_{1}\right)^{2}+\left(7-3 k_{1}\right)^{2}}}{\left(1+6 k_{1}-3 k_{1}^{2}\right)}, \\
\Delta \alpha=\tan ^{-1}\left[\sqrt{3}\left(1-k_{1}\right) /\left(7-3 k_{1}\right)\right] .
\end{gathered}
$$

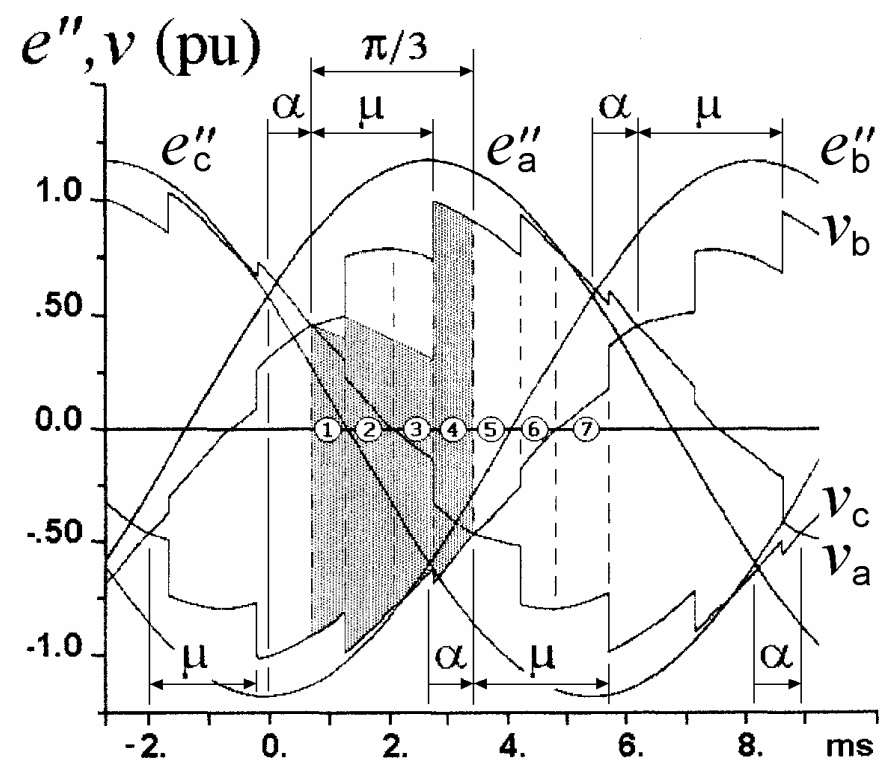

Fig. 3. Rectifier AC side voltage waveforms on Mode II.

During commutation from phase $c$ to $a$ on bridge 1 and commutation from phase $c$ to $a$ on bridge 2 (interval 3 of Figure 3), the terminal voltage is given by: 


$$
\begin{aligned}
& \bar{V}_{a c}=\bar{E}_{a c}^{\prime \prime} \cdot k_{1} \cdot k_{4} \angle \alpha_{c}, \\
& \bar{V}_{b}=\bar{E}_{b}^{\prime \prime} \cdot k_{5} \angle-\Delta \alpha .
\end{aligned}
$$

On intervals 2 and 4 , there is no superposition of commutations and the terminal voltages are given by (8) and (13), respectively.

With above expressions, the rectified average voltage can be obtained by the calculation of the shaded area of Figure 3 and the direct current can be obtained by $v_{a c}$ during the complete commutation $c \rightarrow a$ in bridge 1 , on intervals 1 to 3 . They are given by (1) and (2), where:

$$
\begin{gathered}
A=\frac{(2+\sqrt{3})+2(3+\sqrt{3}) k_{1}-3 \sqrt{3} k_{1}^{2}}{2\left(1+6 k_{1}-3 k_{1}^{2}\right)}, \\
B=\frac{(2 \sqrt{3}+3)-2(\sqrt{3}+3) k_{1}+3 k_{1}^{2}}{2\left(1+6 k_{1}-3 k_{1}^{2}\right)}, \\
C=\frac{(2-\sqrt{3})+2(3-\sqrt{3}) k_{1}+3 \sqrt{3} k_{1}^{2}}{2\left(1+6 k_{1}-3 k_{1}^{2}\right)}, \\
D=\frac{(2 \sqrt{3}-3)-2(\sqrt{3}-3) k_{1}-3 k_{1}^{2}}{2\left(1+6 k_{1}-3 k_{1}^{2}\right)} .
\end{gathered}
$$

\section{Operation Mode III $\left(60^{\circ} \leq \mu \leq 90^{\circ}\right)$}

In Mode III, shown in the Figure 2 (from $46 \mathrm{~ms}$ up to 81 $\mathrm{ms}$ ), two commutations in one six-pulse bridge occur simultaneously with one commutation in the other bridge, in part of the time. On the first commutation overlap (interval 1 on Figure 4, similarly to interval 5), the terminal voltage is:

$$
\begin{gathered}
\bar{V}_{a}=\bar{E}_{a}^{\prime \prime} \cdot k_{1} \cdot k_{6} \angle-\Delta \alpha, \\
\bar{V}_{b}=\bar{E}_{b}^{\prime \prime} \cdot k_{1} \cdot k_{7}, \\
\bar{V}_{c}=\bar{E}_{c}^{\prime \prime} \cdot k_{1} \cdot k_{6} \angle \Delta \alpha,
\end{gathered}
$$

and, on the second commutation overlap (interval 3):

$$
\begin{gathered}
\bar{V}_{b a}=\bar{E}_{b a}^{\prime \prime} \cdot k_{1} \cdot k_{7}, \\
\bar{V}_{c}=\bar{E}_{c}^{\prime \prime} \cdot k_{1},
\end{gathered}
$$

where:

$$
\begin{gathered}
k_{6}=\frac{\sqrt{3\left(1-k_{1}\right)^{2}+\left(7-3 k_{1}\right)^{2}}}{\left(8-4 k_{1}\right)}, \\
k_{7}=1 /\left(2-k_{1}\right) .
\end{gathered}
$$

Intervals 2 and 4 are like in Mode II. The rectified average voltage and direct current are given by (1) and (2), where:

$$
\begin{gathered}
A=\frac{3(2 \sqrt{3}+3)-2(\sqrt{3}+6) k_{1}+3 k_{1}^{2}}{\left(2 / \sqrt{3} \mathrm{k}_{1}\right)\left(1+6 k_{1}-3 k_{1}^{2}\right)}, \\
B=\frac{5(2+\sqrt{3})-2(3+4 \sqrt{3}) k_{1}+3 \sqrt{3} k_{1}^{2}}{\left(2 / \sqrt{3} \mathrm{k}_{1}\right)\left(1+6 k_{1}-3 k_{1}^{2}\right)}, \\
C=\frac{3(2 \sqrt{3}-3)-2(\sqrt{3}-6) k_{1}-3 k_{1}^{2}}{2 \sqrt{3}\left(2-k_{1}\right)\left(1+6 k_{1}-3 k_{1}^{2}\right)}, \\
D=\frac{5(2-\sqrt{3})-2(3-4 \sqrt{3}) k_{1}-3 \sqrt{3} k_{1}^{2}}{2 \sqrt{3}\left(2-k_{1}\right)\left(1+6 k_{1}-3 k_{1}^{2}\right)} .
\end{gathered}
$$

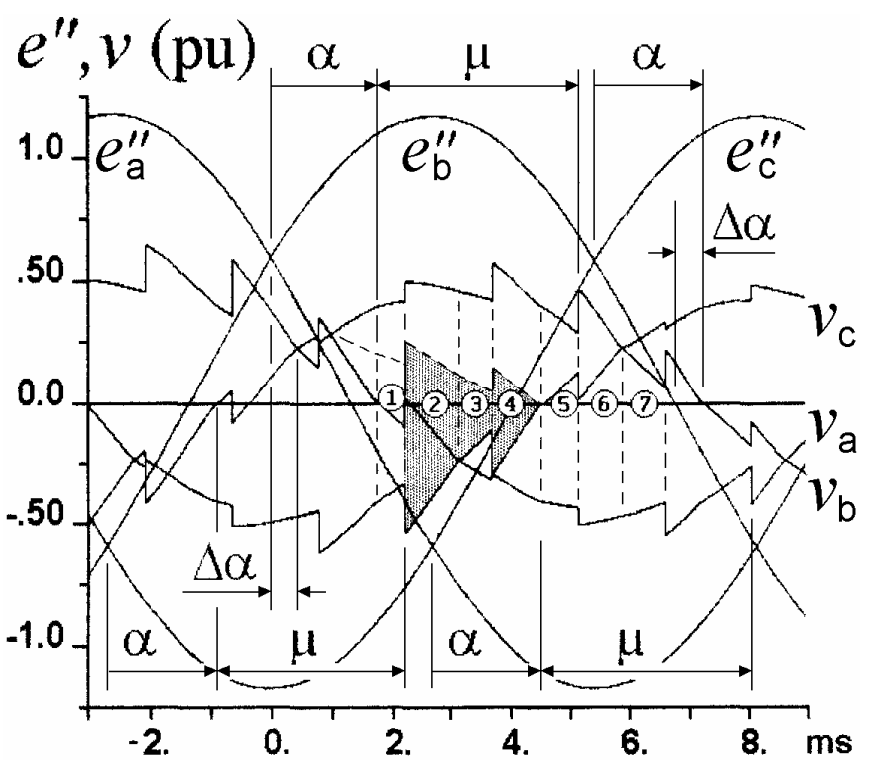

Fig. 4. Rectifier AC side voltage waveforms on Mode III.

\section{Operation Mode IV $\left(90^{\circ} \leq \mu \leq 120^{\circ}\right)$}

In Mode IV, shown in the Figure 2 (after $81 \mathrm{~ms}$ ), the threephase short-circuits of each bridge occur simultaneously. On these intervals (intervals 1, 3, 5, 7 on Figure 5), the rectified voltage is null and the machine terminal voltage is given by:

$$
\bar{V}_{a}=\bar{E}_{a}^{\prime \prime} \cdot k_{1} \cdot k_{7} .
$$

On intervals 2, 4, 6 on Figure 5, the terminal voltages are given by expressions of Mode III.

Then, in this operation mode, the rectified average voltage and direct current are given by (1) and (2), where:

$$
\begin{gathered}
A=3 k_{1} / 2, \\
B=\sqrt{3} k_{1} / 2, \\
C=1 /\left[2\left(2-k_{1}\right)\right], \\
D=1 /\left[2 \sqrt{3}\left(2-k_{1}\right)\right] .
\end{gathered}
$$

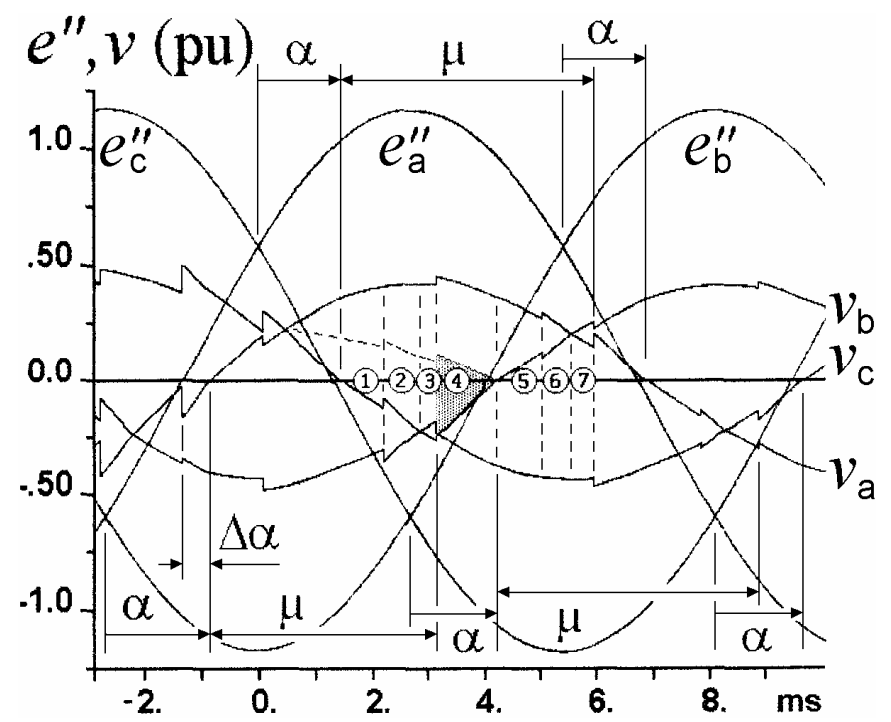

Fig. 5. Rectifier AC side voltage waveforms on Mode IV. 


\section{UC OPERATION CHARACTERISTICS}

Figure 6 shows the volt-ampere characteristic curve (rectified average voltage versus direct current) obtained with above expressions for the case of minimum firing angle $\alpha_{\mathrm{m}}$. In this figure, all operating regions described in Table I are presented for the system shown in the Appendix (in this example, $x "=0.24 \mathrm{pu}, x_{\mathrm{t}}=0.15 \mathrm{pu}, k_{1}=0.556$, and the coupling factor $\left.K=\left[1-k_{1}\right]=0.444\right)$. In the regions with constant minimum firing angle (Regions $\mathrm{A}, \mathrm{C}, \mathrm{E}, \mathrm{F}$ ), the relation between rectified voltage $V_{d}$ and direct current $I_{d}$ is represented by a straight line. The others Regions B and D (with constant commutation angle) are characterized by curves.

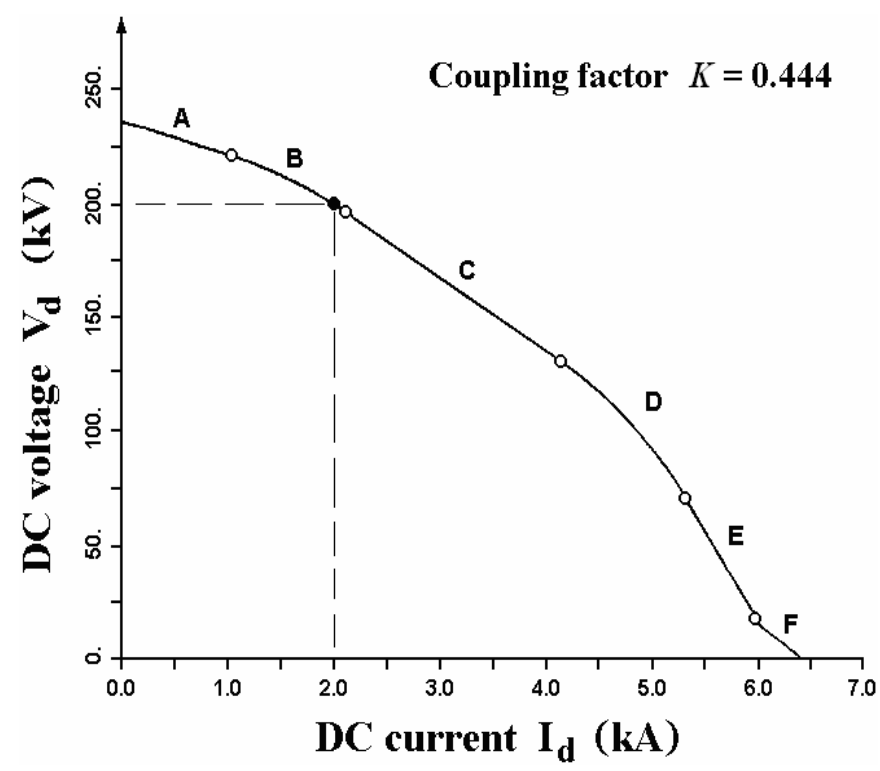

Fig. 6. Rectified DC voltage versus direct current, characteristic curve for the system described in the Appendix.

Depending of value of the coupling factor, some regions may not exist. Analyzing expressions (12) and (19) and observing Table I, some intervals of minimal firing angle become inexistent or impossible for some values of $k_{1}$ (or $K$ ). For a null coupling factor $K=0$ (when $k_{1}=1$ and $\alpha_{c}=\Delta \alpha=0^{\circ}$ ), which is the case of a conventional systems (with AC filters and without mutual reactance), Region $\mathrm{B}$ does not exist (because the interval $\left[0^{\circ} \leq \alpha_{m} \leq \alpha_{c c}\right]$ on Table I becomes inexistent) and Regions $\mathrm{A}$ and $\mathrm{C}$ are the same. Similarly, Regions $\mathrm{E}$ and $\mathrm{F}$ are both represented by the same expressions.

For a unitary coupling factor $K=1$ (when $k_{1}=0, \alpha_{c}=60^{\circ}$ and $\Delta \alpha \approx 13,9^{\circ}$ ), only Regions $\mathrm{A}, \mathrm{B}$ and $\mathrm{C}$ exist (interval $\left[\alpha_{c} \leq \alpha_{m} \leq 30^{\circ}+\Delta \alpha\right]$ of Region $\mathrm{D}$ on Table I becomes impossible) and Region B is predominant. This is the case when the machine is specially designed for a connection to the converter without transformers [11].

But Region D do not becomes inexistent only for $K=1$. Analyzing expressions (12) and (19), the interval $\left[\alpha_{c} \leq \alpha_{m} \leq 30^{\circ}+\Delta \alpha\right]$ on Table I becomes impossible when:

$$
\alpha_{c}>\pi / 6+\Delta \alpha \Leftrightarrow K>\sqrt{2 / 3} \text {. }
$$

\section{UNIT CONNECTION WITH DIODE RECTIFIER}

The operation characteristic of the UC shows that it has an inherent self-regulation. For the Unit Connection with diode rectifier (Diode UC) this fact is very useful because the natural delay and commutation angles increase for large currents and, during short-circuits, the rectified voltage is automatically reduced.

In the Diode UC, the diode valves have a natural delay angle $\alpha_{n}$, which is the same minimum firing angle $\alpha_{m}$ expressed before for thyristors valves, exactly as shown in Table I and Figure 6. In the typical case presented in the Appendix, the operating point is on Region B, where expressions of Mode I are valid. For this specific Region where $\mu=\pi / 6$, the natural delay or minimum firing angle, with (4) and (7), is given by [5]:

$$
\alpha_{n}=\sin ^{-1}\left[\frac{X_{c} \cdot I_{d}}{\sqrt{2} E^{\prime \prime} \sin (\pi / 12)}\right]-\frac{\pi}{12} .
$$

In steady state, the sub-transient voltage $E$ ” is proportional to the field voltage $V_{\mathrm{f}}$. Therefore, observing (6), we can see that there are two ways for this field voltage to affect directly the rectified average voltage, one affecting directly the parameter $V_{d o}$, as is expressed in (3), another affecting inversely the natural delay angle $\alpha_{n}$, as shown in (39), which is the same delay angle in (6). The additional influence due to the natural delay angle, given above, improves the Diode UC operating point control of by the machine field voltage.

Figure 7(a) shows the 12-pulse Diode Unit Connection DC average voltage. In this case, for DC current smaller than $2 \mathrm{kA}$, the generator field voltage is kept constant and the DC voltage varies according to this DC current. For DC current equal to $2 \mathrm{kA}$, the generator field voltage is controlled, as shown in Figure 7(b), in such a way as to make the rectifier operate as a constant current source, with the desiderated DC average voltage. The inverter in the other extreme of DC line does the current control. This figure shows that field voltage as low as $0.35 \mathrm{pu}$ is enough to produce a null rectified voltage.

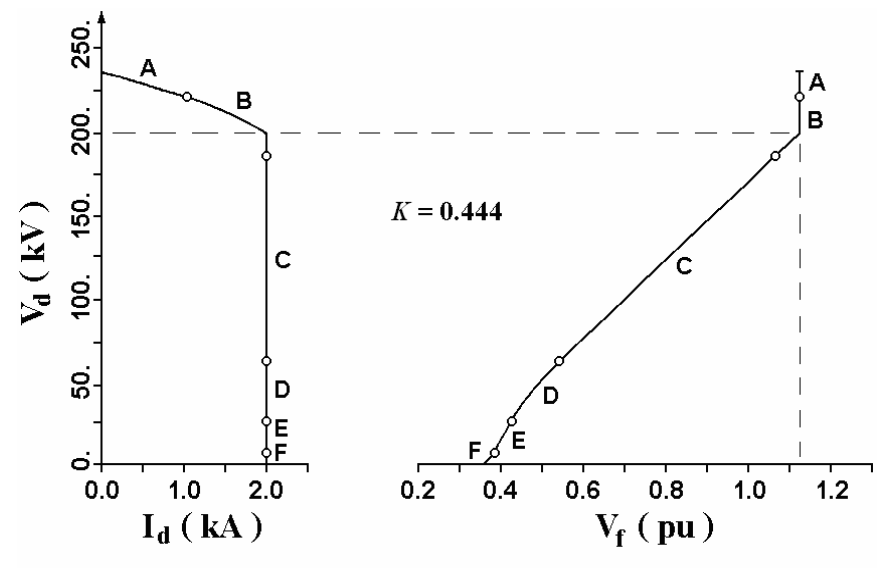

(a)

(b)

Fig. 7. Twelve-pulse Diode Unit Connection controlled by the machine field voltage.

In this case, the operating point is in the Region B but very close to its limit, and the control of DC average voltage 
will be predominantly in Region C. However, Region B is better to operate, because in this Region the control is with variable natural delay angle, the commutation angle is smaller and constant $\left(30^{\circ}\right)$ and there are less valves conducting because there are not superpositions of commutations (important parameters to UC design). Hence, the Diode UC can be designed with a wider margin of control inside Region B (up to $140 \mathrm{kV}$ ) if $K=0.5$, as shown in Figure 8 . This coupling factor can be obtained by adequate choice of machine and transformer parameters $\left(x^{\prime \prime}=0.30 \mathrm{pu}\right.$, $x_{\mathrm{t}}=0.15 \mathrm{pu}$ ). Another form to change the coupling factor is by correctly choosing the mutual reactance of the three-winding transformer, to increment the effective commutation reactance.

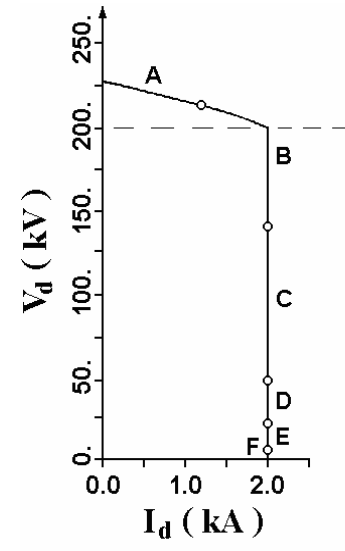

(a)

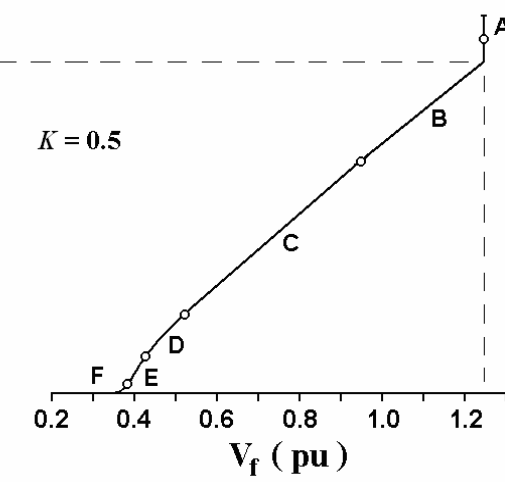

(b)
Fig. 8. A optimized design of twelve-pulse Diode Unit Connection controlled by the machine field voltage.

\section{CONCLUSIONS}

As shown in this work, in twelve-pulse Unit Connection there are four operation modes, if we consider its constitutive expressions only (at fixed minimum firing angle), or six operation regions, if we include the transition between those modes (at constant commutation angle).

This present paper contributes to a better elucidation of this operating modes and regions. It was shown that the distorted terminal voltage of the machine, the rectified voltage and direct current of the converter can be fully determined by simple and original analytical expressions for all operation modes. This set of equations is very precise and useful to determine the UC operating characteristics, to define the operating point and explore self-regulation possibilities of its direct current. These equations are also useful to design de UC configuration (with thyristor or diode valves), including the selection of the bridges' coupling factor, by adequate choice of the machine and the mutual reactance of three-winding transformers.

\section{ACKNOWLEDGMENTS}

The authors wish to acknowledge the technical support given by ELETRONORTE and CEPEL, as well as acknowledge the encouragement and help received from Dr. João Guedes Campos Barros. This work was partially supported by PRONEX/CNPq, CNPq and FAPERJ.

\section{APPENDIX - SYSTEM DATA}

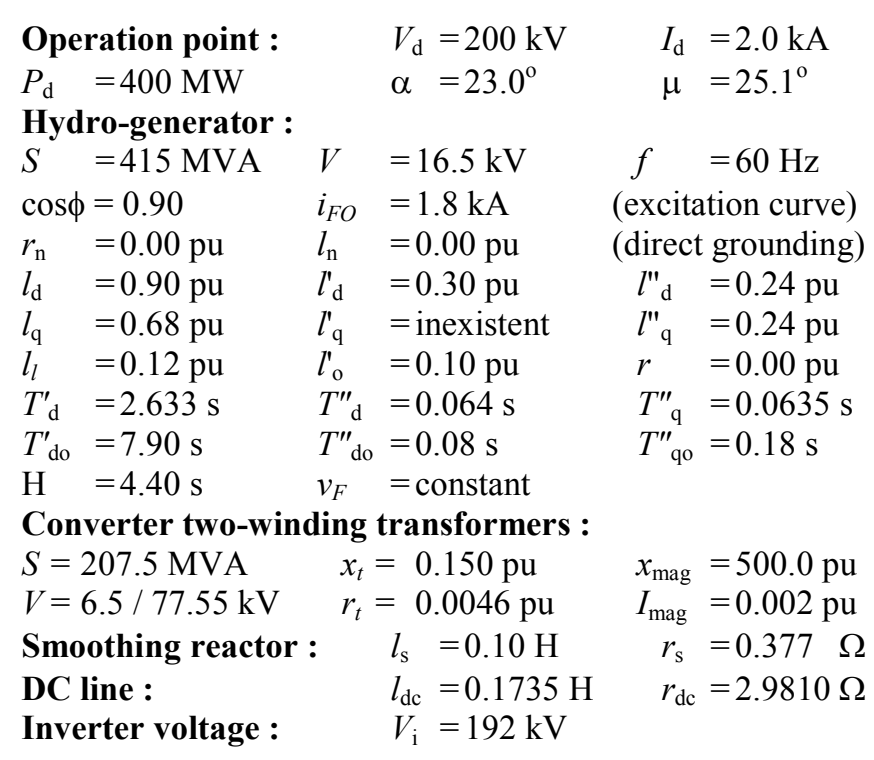

\section{REFERENCES}

[1] Lineu Belico dos Reis, "Towards a Sustainable Integration of Large Energy Projects to Local Small Energy Systems". 19 $9^{\text {th }}$ World Energy Congress, Sydney, Australia, September 2004.

[2] CIGRÉ Joint Working Group 11/14-09, "HVDC Unit Connected Generators". Electra, 149, August 1993.

[3] CIGRÉ Joint Working Group, "Guide for Preliminary Design and Specification of Hydro Stations with HVDC Unit Connected Generators", Cigré, 116, August 1997.

[4] J. Arrillaga, J. Bowles, J. G. Campos Barros, K. W. Kanngiesser and L. Ingram, "Direct connection of generators to HVDC converters: main characteristics and comparative advantages". Electra, 149, August 1993.

[5] J. Daldegan Jr., A.S. Pedroso and E. H. Watanabe, "Frequency and Time Domain Analysis of Unit Connected Generators to HVDC Converters", IEE Proceedings on Generation, Transmission and Distribution, vol. 150, pp. 1-6, Issue 1, January 2003.

[6] Q. N. Dinh, J. Arrillaga, "Factors affecting the commutation reactance of direct connected generatorconverter units", IEEE Transactions on Power Delivery, Vol. 14, No. 3, pp. 1090-1095, July 1999.

[7] E. W. Kimbark, "Direct Current Transmission", Wiley-Interscience, New York, pp. 102 - 103, 1971.

[8] Freris, L. L., "Effects of Interaction Among Groups in a Multigroup AC-DC Converter", IEE Proceedings, vol. 114, no. 7, pp 965-973, July 1967.

[9] J. G. Campos Barros and R. D. Rangel, "Computer Simulation of Modern Power Systems: the Elimination of Numerical Oscillations Caused by Valve Action", Proceedings of Fourth International Conference on AC/ DC Power Transmission, pp. 254-259, London, 1985.

[10] J. Daldegan Jr., "Converters and Synchronous Generator in Unit Connection for HVDC Systems" (in Portuguese), D.Sc. Thesis, COPPE/UFRJ, March 1999.

[11] M. Naidu, R. M. Mathur, "Unit Connection of a Double Three Phase Generator to HVDC Converters", IEEE Montech'86, Conference on HVDC, September 1986. 


\section{BIOGRAPHIES}

José Daldegan Júnior was born in Brasília, Brazil, in 1962. Received his B.Sc. in Electrical Engineering in 1984 from the University of Brasília; received his M.Sc. and D.Sc. in Electrical Eng. from the Federal University of Rio de Janeiro, in 1992 and 1999 respectively, both related to Power Electronics Applied to Power Systems.

From 1985 to 1988 he worked at a consulting company of power systems. Since 1989 he works on the Eletronorte - a Brazilian Holding Electric Power Co., studying the transmission systems in the north of the Brazil.

Dr. Daldegan was member of the CIGRÉ Joint Working Group 11/14-09 which systematized a guide for preliminary design and specification of hydro stations with HVDC unit connected generators.

Edson Hirokazu Watanabe was born Brazil in 1952 and received the B.Sc. in Electronic Eng. and the M.Sc. in Electrical Eng. from Federal University of Rio de Janeiro (UFRJ) in 1975 and 1976, respectively. In 1981 he received the D. Eng. degree in Electrical Eng. from Tokyo Institute of Technology, Japan.

Since 1981 he is a Professor of the Federal University of Rio de Janeiro (UFRJ), and his fields of interests are Power Electronics Applied to Power Systems, including active power filters, HVDC systems and FACTS.

Dr. Watanabe is a Senior Member of the IEEE and member of Power Engineering, Power Electronics and Industry Applications Societies. He is also a member of the Institute of Electrical Engineers, Japan (IEEJ), the Brazilian Society for Automatic Control, the Brazilian Power Electronics Society and CIGRE. 